To study the feasibility of such a clinic we looked at 104 consecutive dermatological referrals (August 1992 to February 1993) from doctors working in the practice (as part of the fundholding data collection exercise we have kept copies of all ou referral letters). The referring doctors included trainee general practitioners and locums as well as the partners. Of the 104 referral letters, 91 (88\%) offered a diagnosis, compared with Russell Jones's figure of $40 \%$. We received letters about 54 patients. In 33 of these the diagnosis offered was confirmed by the consultant, giving a diagnosic accuracy of $61 \%$ compared with the $27 \%$ quoted by Russell Jones. Eighteen patients had a skin biopsy or had a lesion removed, but no tests other than the usual histological examination were necessary. Twenty six patients were given follow up appointments, either to assess treatment or to give the results of histological examination.

The waiting times for NHS appointments varied between 2 weeks (for those patients for whom urgent appointments were requested) and 21 weeks, with a mean of 13 weeks. Disturbingly, however, 27 patients who had been referred between August and December had still not been seen by the end of the study. Perhaps these were non-attenders, but if so we have not yet been notified by the hospitals.

It is rare in general practice to see dermatological problems that need sophisticated hospital investigations or intensive treatment; most referrals are for assessment of skin lesions or for second opinions. Seeing patients in general practitioners' surgeries is no different from seeing patients in private consulting rooms-a practice that fails to provoke outrage among dermatologists. A well run community service can deal effectively with mos skin problems. Most cases would not require hospital follow up, as our figures show. This would allow dermatologists to concentrate resources on patients who need the technical support available in hospitals.

SUSAN ALLAN NEIL CROWLEY FRANCES CARTER JEREMY GITTINS

The Surgery,

London W5 1TP

Russell Jones R. Community dermatology. BMY 1993;306:586. (27 February.)

\section{Academic obstetrics and gynaecology}

EDITOR,-In his comments on Richard Smith's editorial on academic medicine ${ }^{1}$ Brian L Pentecost states that, so far as training for consultant practice in the NHS is concerned, all specialties accept one year of research towards higher medical training. ${ }^{2}$ This is not true. The accreditation regulations of my college, the Royal College of Obstetricians and Gynaecologists, allow for up to one year of research during which the candidate has undertaken a regular clinical obstetric and gynaecological commitment. I have spent three and a half years in research, leading to a $\mathrm{PhD}$ in molecular biology. The research itself was laboratory based, although directly relevant to academic obstetrics. During that time I held honorary NHS senior registrar status and, to maintain my clinical skills, was on call once a week as a resident registrar in obstetrics and gynaecology and did a full day's operating list once every two weeks. Although this would seem to fulfil the requirements of the regulations, my application to have this experience recognised for just six months of higher training was rejected by the college without explanation.

In contrast, subspecialty trainees, undergoing training in the same institution and at the same time, are allowed a full year of credit but are not expected to undertake any general obstetrics and gynaecology during their subspecialty years. This seems to indicate that the college considers that a subspecialist trainee can acquire general skills in a shorter time than an academic trainee. There is an attitude of discrimination against academics within our specialty, highlighted recently by Thomas. ${ }^{3}$ Although academic consultant appointments do not require accreditation, stigma is attached to those people who are not accredited. There is a dire need to encourage juniors into academic obstetrics and gynaecology. The number of vacant senior lectureships and chairs attests to this. Until the specialty and, more importantly, the college recognise the value of an academic career and are willing to regard academics as equals, academic obstetrics and gynaecology will be an unpopular choice and will remain in the scientific shadow of medicine and surgery.

Queen Charlotte's and Chelsea Hospital,

PHILLIP BENNETT

London W6 0 XG

1 Smith R. Academic medicine: plenty of room at the top. $B M \mathcal{J}$ 1993;306:6. (2 January.)

2 Pentecost BL. Academic medicine. BMF 1993;306:583. (27 February.)

3 Thomas E. The role of research in the training of an obstetrician and gynaecologist. Br F Obstet Gynaecol 1993;100:35-6.

\section{Continuing education needed for forensic medical examiners}

EDITOR,--The Today radio programme has reported that police surgeons or forensic medical examiners are to call for a ban on methadone for prisoners in police custody. This is a response to the conviction of two forensic medical examiners of the manslaughter of a prisoner for whom they had prescribed methadone.' They had not, however, been trained in forensic medicine, and they prescribed several drugs in excessive doses after the prisoner had already been withdrawn from opioid drugs. I urge that there should be no such hasty reaction to what is not only a tragedy for the patient and his family but a tragedy for two medical practitioners, their families, and their peer group of forensic medical examiners.

Practical, legal, and ethical difficulties arise in the management of supposed drug dependent people in custody. A naive acceptance of what the prisoner says, especially when the supply has been illicit or there is no prescriber to consult, may result in overprescription of drugs intended for maintenance or withdrawal but resulting in intoxication or perpetuation of dependence, or both. A decision not to prescribe or an underestimate of need, with justified caution, may aggravate or precipitate a distressing withdrawal state, which a doctor has a responsibility to prevent or relieve, and may make the prisoner unfit to be interviewed.

Ideally, opioid dependent prisoners in custody should be stabilised with the right dose. If they have been taking a prescribed drug this is likely to have been methadone, and if the daily dose can be established this can be prescribed. If there is uncertainty about the dose it may be wise to prescribe methadone $20 \mathrm{mg}$ and then review this in the light of the response. To prescribe nothing could be unethical, uncaring, and perilous in terms of the investigation of the case and the pursuit of truth. Some forensic medical examiners, however, are reluctant to prescribe methadone. Some prefer dihydrocodeine, but this substitutes so poorly that large quantities may be needed, and it often leaves many prisoners suffering considerably. Although methadone can be given in police custody only under supervision, its advantage is that it needs to be given only once daily.

I hope that the advice of the Advisory Council on the Misuse of Drugs will be sought. Surely the most important issue, however, is the training and continuing medical education of forensic medical examiners. There are diplomas in medical jurisprudence and forensic medicine and excellen courses of preparation such as that run by the Forensic Academic Group in the North. If there is any hasty reaction it should be a requirement that all forensic medical examiners are properly trained and have provision for continuing medical education.

KEITH J B RIX

Department of Psychiatry

St James's University Hospital

Leeds LS9 7TF

1 Dyer $C$. Police surgeons sent to jail for manslaughter. $B M \mathcal{F}$ 1993;306:415-6. (13 February.)

\section{Male obstetricians and their patients}

EdIToR,-It is true, as James Owen Drife points out, that it has become at least partially acceptable for women to stereotype the worst of male behaviour and make fun of it, but somehow I find it hard to feel sorry for him. ' As almost every woman who has ever complained about jokes against women has been told, "Where's your sense of humour?"

Part of the problem lies in his opening statement: "Eighty seven per cent of consultant obstetricians in Britain are male." Any complaint about medical treatment thus almost certainly is a complaint against a man. Does he really believe that the woman who spent an hour asking questions would have passively accepted everything a female consultant told her with no queries? If there is power imbalance between patients and doctors this is doubly so between male doctors and female patients. If male doctors have difficulty accepting or understanding this it is probably because they have not been in such powerless positions since childhood. Drife should not be surprised that many women respond to a strange man with a conditioned response that arises from a long learning experience in a male dominated society. Many women have learnt to be wary and to offer trust slowly. Why, simply because he is a doctor, should he assume that women will come as trusting, respectful, and, above all, compliant patients who can be dealt with quickly?

Despite this Drife should take heart from the cartoons in the journals. It has long been accepted that people make jokes about what frightens them and that groups who feel oppressed use humour as a way of releasing negative feelings to those in power. He should hope that such cartoons continue. While women use them as a way of releasing tension, frustration, and rage they will have the illusion of doing something while nothing changes.

A better solution to female patients being hostile to middle aged male obstetricians, of course, is to ensure that in the coming generation of doctors $87 \%$ of obstetric consultants are female.

JACQUELINE M ATKINSON

Department of Public Health

University of Glasgow,

Glasgow G12 8RZ

1 Drife JO. Suffering stereotypes. BMf 1993;306:591
(27 February.)

\section{Correction}

\section{Drugs, secrecy, and society}

An editorial error occurred in this letter by J Kilgour Christie and A H Watt (13 March, pp 721-2). The first sentence of the fifth paragraph, which started "Risk attributable to drugs is poorly estimated," should have started "Risk attributable to disease is poorly estimated." 